\title{
The road to independence: Lived experiences of youth with chronic conditions and their parents compared
}

\author{
Mariëlle A.C. Peeters ${ }^{\mathrm{a}}$, Sander R. Hilberink ${ }^{\mathrm{a}}$ and AnneLoes van Staa ${ }^{\mathrm{a}, \mathrm{b}, *}$ \\ ${ }^{a}$ Research Center Innovations in Care, Rotterdam University of Applied Sciences, Rotterdam, the Netherlands \\ ${ }^{\mathrm{b}}$ Institute of Health Policy \& Management, Erasmus University Rotterdam, Rotterdam, the Netherlands
}

Accepted 7 February 2014

\begin{abstract}
.
PURPOSE: To gain insight into the development of young persons with chronic conditions towards independence by comparing their lived experiences to those of their parents.

METHODS: Semi-structured interviews were held with 16 young persons ( 7 males, 9 females; $15-22$ years) and one of their parents $(n=16)$, asking about the young persons' daily lives and their development towards adulthood. Themes were deductively derived from the Skills for Growing Up framework, i.e. agency, living and daily activities, social and intimate relationships, education, work, leisure activities, transportation, and healthcare. Parents also reflected on how they dealt with the child's chronic condition. A paired thematic analysis was conducted.

RESULTS: Parents were often less convinced that their children could act independently than the young persons themselves. They were concerned about them and tended to interfere with their daily lives, often to the annoyance of their children. Also, parents often perceived more barriers in social participation, while young persons were more positive.

CONCLUSION: The perceptions of young persons and their parents clashed on living independently, intimate relationships, leisure activities, and healthcare. Young people might benefit from professional support in these domains to help them strengthen their autonomy and to prevent child-parent conflict and negative outcomes.
\end{abstract}

Keywords: Young persons, chronic conditions, parents, transition, lived experiences

\section{Introduction}

Every young person's development naturally includes a process of transition towards independence. However, for young people with chronic conditions transition may be challenged by their health situation $[1,2]$. They often achieve fewer developmental milestones, face more restrictions in social participation compared to healthy peers [3-7], and may lag behind in education and work, independent living, and

* Corresponding author: Anne Loes van Staa, Centre of Expertise Innovations in Care, Rotterdam University, P.O. Box 25035. 3001 HA Rotterdam, The Netherlands. Tel.: +31 1079441 70; E-mail: a.van.staa@hr.nl. relationships [8-12]. The extent of this delay may depend on the severity of the chronic condition; the greater the number of neurocognitive impairments or the more severe the physical limitations, the more delayed the young person's development $[5,13,14]$. Lagging behind, in turn, is negatively associated with level of peer contact, self-efficacy, independent behavior, and self-respect $[6,13,15]$, and might also lead to less social participation and negative prospects in adulthood $[6,8,11,16]$.

Gaining independence from parents requires a role change on the part of both parent and child. Parents are expected to gradually give their children more responsibilities $[2,17,18]$. This may be hard for parents of children with chronic conditions to accept, especially 
when their child has special needs [19]. Parents may perceive their child to be more vulnerable, and may wish to remain in control of the complex and often unpredictable medical situation. Furthermore, parents' concerns may be reinforced by their child's social immaturity and limited self-care skills as compared with able-bodied peers [20-22].

The young people themselves are often more positive about becoming independent than their parents [20]. While they tend to focus on their abilities, parents seem to emphasize their child's disabilities [23]. These divergent perceptions may result in child-parent conflicts. While parents may attempt to retain responsibility for the management of their child's chronic condition, children feel this unnecessarily limits their independence and participation in social life [24,25]. Nevertheless, the children themselves do recognize possible cons of the chronic condition, especially in adolescence, when relationships are being negotiated and redefined [21]. At a time when able-bodied peers establish their independence and assert themselves in an expanding environment, they may find themselves in a situation of enforced dependency that impedes their development towards autonomy. Peers can help them to become independent by taking over tasks from parents and offering support [26].

Thus, there seems to be a conflict between parental focus on limitations and risks on the one hand, and the child's perspective on living a 'normal' life and shaping participation on the other hand. To our knowledge, no studies have explored how the views of young persons with chronic conditions on achievement of adult roles in social participation and self-care may disagree with those of their parents. Therefore, the objective of this study was to gain more insight into the process of achieving independence by comparing the lived experiences of young persons to those of their parents.

\section{Methods}

\subsection{Study design and setting}

The present study draws on data collected in a study of Van Staa et al. [27] describing experiences with transition of care. That study was a qualitative multiple case study among young persons with chronic conditions and their parents in the Erasmus Medical Center Rotterdam - Sophia Children's Hospital. Seven diagnostic groups were included: diabetes mellitus (DM), spina bifida (SB), congenital heart disorders (CHD), cystic fibrosis (CF), juvenile idiopathic arthritis (JIA), hemophilia (HP), and sickle cell disease/thalassemia (SCD). In the current study, young persons with HP were not included since no paired comparisons could be established between these young persons and their parents. Young persons were eligible for inclusion if they did not have an intellectual disability and if they had transferred from pediatric care to adult care in the past two years. At the time there were no structured transition programs; departments started discussing the impending transfer no earlier than six to twelve months in advance. The timing of the transfer differed between chronic conditions: SB patients were discharged at 15-16 years; in other departments patients were usually transferred around 18 years, the age at which they graduated from secondary education. Also, regarding the latter criterion, at the time of the study, patients with $\mathrm{CF}$ could not yet be transferred to adult services. Hence, young persons over the age of 18 with CF who were on the waiting list for transfer were invited.

Young persons and their parents participated in semi-structured interviews administered by nursing students after extensive training and under supervision. Child and parent were interviewed separately for 45 to 120 minutes at the participants' homes. The interviews were digitally recorded and fully transcribed at verbatim.

\subsection{Study sample}

Three young persons were randomly selected from each of five diagnostic groups of patients that had been transferred to adult care in the past two years. For each young person, one parent participated in the study. The young persons proposed which parent could be invited. Young persons from the $\mathrm{CF}$ group were randomly selected from the waiting list. A reminder letter was sent to non-responders after two weeks, followed by a telephone call a few days later. If the young person could not be reached or did not consent to participate, another patient was randomly selected. This procedure was repeated until three participants per diagnostic group were secured. In the SB group, however, three extra participants were invited, because during the interviews it appeared that the participating SB patients had not yet visited adult care.

All invited CF patients consented, but in the other patients groups response rates varied between 30$60 \%$ [27]. The main reason for non-participation was limited interest in the study, notably from those under the age of 18 and those with limited disease ac- 
tivity. Moreover, some $50 \%$ of the initially selected DM and SCD patients could not be reached by mail or phone [27]. Parents of 17 of the 21 young persons participating in the interviews were interviewed as well. One parent interview was not included in the analysis because of insufficient comprehension of the Dutch language. Therefore, 16 child-parent comparisons could be made.

\subsection{Data collection}

Young persons and their parents were interviewed separately. Interviews proceeded along the lines of an interview protocol focused on the young persons' daily lives and their development towards adulthood. Issues addressed were covered by two transcending themes: social participation and participation in care. The first theme included more general issues about the young persons' daily lives and their transition towards adulthood, whereas participation in care focused specifically on healthcare issues. The latter paid attention to self-management, defined as "the way you deal with your chronic condition and your capability to take responsibility for all problems and issues your condition entails". For each issue, Table 1 presents one sample question. The parents' interviews addressed the same issues. In addition, parents were invited to reflect on their way of dealing with their child's chronic condition.

\subsection{Data analysis}

Pair-wise comparisons were made with methods of agreement and difference [28-30]. The data analysis was guided by the Skills for Growing Up (SGU) framework, which encourages autonomy development in nine life areas: 'me' (agency), 'healthcare', 'relationships', 'education', 'work', 'living and daily life activities', 'transportation', 'leisure activities', and 'sports' [7,31]. These life areas are compatible with the issues young persons and their parents were asked about, except for sports. The interviews gave little information on this issue, so it was excluded from analysis. Eventually, four main categories were established: (1) agency and self-reliance; (2) studying and working; (3) leisure and social relationships; and (4) healthcare and self-management (see Table 1). The analysis was performed by the first author (MP) and the findings were continually discussed with the entire research team.
ATLAS.ti 6.0 (www.atlasti.com) was used for data analysis. One interview with a young person followed by one interview with a parent was coded based on the SGU framework, and the similarities and differences were identified [28-30]. For a better comparison, the young person's and parent's quotes were also placed in a so-called contrast table, as recommended by Miles and Huberman [30]. The results of this contrast table are discussed in the results section below.

\subsection{Ethical considerations}

The Institutional Review Board of the Erasmus University Medical Center has approved the study protocol (MEC-2004-343). All study participants gave written informed consent. For young persons under 16, parents also provided written consent. Researchers had no access to hospital data about the study participants, and confidentiality and anonymity were assured to all of them.

\section{Results}

\subsection{Study sample}

Table 2 presents the characteristics of the 32 study participants: 16 young persons (YPs), of whom 7 males (M) and 9 females (F), and 16 parents $(\mathrm{P})$. All parents but one were mothers. The mean age of the YPs was 18.3 years ( $\mathrm{SD} \pm 1.9$ ), range $15-22$ years. Fourteen were still studying; the other two had jobs.

\subsection{Agency and self-reliance}

Parents recognized a negative impact of the chronic condition on the YP's self-respect, for instance related to social taboos:

YP (F; 17; SB): Incontinence is hardly socially acceptable. A seventeen-year-old [...] still wetting the bed, that's weird.

P: [My daughter] would have gone to a special school if she had lost self-respect on account of reactions of others to her incontinence. Fortunately, it didn't get to that point.

However, YPs generally saw themselves as "normal' and this was mainly achieved by contact with able-bodied peers. Parents were satisfied with the YPs' sense of self-respect, although parents sometimes underestimated it. Many YPs perceived the chronic condition as 'something that belongs to me'. Still, the perceptions of YPs and their parents on this issue occasionally conflicted: 
Table 1

Sample questions per issue addressed during the interview

\begin{tabular}{|c|c|}
\hline Issue & Sample question \\
\hline \multicolumn{2}{|l|}{ Social participation } \\
\hline \multicolumn{2}{|l|}{ Agency and self-reliance } \\
\hline Agency & What is the role of your parents in your life? \\
\hline Living and daily life activities & What are your future plans regarding living? \\
\hline \multicolumn{2}{|l|}{ Studying and working } \\
\hline Education & Do teachers and fellow students take your condition into account? \\
\hline Work & What are your future plans regarding work? \\
\hline \multicolumn{2}{|l|}{ Leisure and social relationships } \\
\hline Leisure activities & How do you spend your leisure time? \\
\hline Social and intimate relationships & Does your condition restrict you from entering into social relationships? \\
\hline Transportation & Do you organize transportation yourself or do your parents organize it for you? \\
\hline \multicolumn{2}{|l|}{ Participation in care } \\
\hline \multicolumn{2}{|l|}{ Healthcare and self-management } \\
\hline Healthcare & How independent are you in dealing with your condition? \\
\hline
\end{tabular}

Table 2

Background characteristics of 32 study participants (2004-2007, Erasmus MC - Sophia Children's Hospital)

\begin{tabular}{lcc}
\hline & $\begin{array}{c}\text { Young } \\
\text { persons }\end{array}$ & Parents \\
\hline Number of participants & 16 & 16 \\
Male/female & $7 / 9$ & $1 / 15$ \\
Treatment setting: pediatric care/adult care & $6 / 10$ & \\
Chronic condition (age in years) & & \\
$\quad$ Diabetes mellitus (18-20 y) & 2 & 2 \\
Spina bifida (15-17 y) & 6 & 6 \\
Congenital heart disorder (22 y) & 1 & 1 \\
Cystic fibrosis (18-20 y) & 3 & 3 \\
Juvenile idiopathic arthritis (18-19 y) & 3 & 3 \\
Sickle cell disease/thalassemia (21 y) & 1 & 1 \\
Young person's characteristics & & \\
Age (in years) & & \\
$\quad$ 15-18 & 9 & \\
$\quad$ 19-22 & 7 & \\
Living at home/living independently & $12 / 4$ & \\
Studying/working & $14 / 2$ & \\
Relationship: yes/no/unknown & $9 / 5 / 2$ & \\
\hline
\end{tabular}

YP (F; 18; JIA): I don't feel ashamed of my disease; I'm totally open about it.

P: Often, [...] when others are around, she feels a bit ashamed [about her disease], shy to acknowledge that she's different from others.

YP (F; 19; JIA): Mostly I don't talk about my disease with other people.

$\mathrm{P}$ : She is very open [about her rheumatic disorder] and I think she deals well with it.

Living independently was perceived as a logical step to adulthood. Some YPs already lived independently and others said they would like to, and their parents agreed on this:

YP (F; 19; JIA): I'm not visiting my parents every weekend, only once every two or three weeks or something.
P: I think it's obvious that [my daughter] is very independent.

However, sometimes parents saw it differently from their children and resorted to overprotection:

YP (F; 21; SCD): I think I'm an adult and it's time to [leave home]. I'm living with my mother now and it seems like I'm really dependent on her, as if I can't manage myself. But I want to try to live independently.

P: [My daughter] has plans to live independently, but I think she is not ready yet. Maybe within a few years or so, after she has finished school.

Some YPs wished to live independently, but felt hindered by their chronic condition. Others however, especially the persons with SB, were more reluctant towards living independently. They had 'no need' to leave home because it felt 'safe' at home, a situation reinforced by their parents being protective:

YP (M; 17; SB): Anyway, I'm too young for that, yeah seventeen, but at twenty it will still not be feasible. Only when I'm about thirty, forty years old, maybe...

P: We don't think he's ready to live independently, because, for one thing, he will be fully isolated then and secondly he needs help [...] in his daily living activities, otherwise he just forgets it.

\subsection{Studying and working}

Some YPs had limited study or work possibilities and others noted that fellow students or colleagues doubted the seriousness of the condition in view of the fluctuations in presentation. Many parents confirmed that their children faced lots of challenges, and several 
parents expressed concerns about study and work opportunities:

YP (F; 20; CF): I am too tired to concentrate all the time $[\ldots]$. I have not been to school for a very long time. I only sit examinations sometimes, in the hospital or at school. I do not attend lectures anymore, nothing at all.

P: I hoped that [my daughter] would get better when studying at university [...], just like when she was at secondary school. But now, it's very difficult for her. I think it's terrible.

YP (M; 18; DM): I just go to school from Monday till Thursday. On Friday and Saturday, most of the time I go to work.

P: I hope he will not have problems when applying for a job later, because that's what you hear sometimes. All right, he has a chronic disease and often employers don't know exactly what it is. When you are disabled, they don't want you anymore, because you are a burden.

\subsection{Leisure and social relationships}

YPs sometimes felt like being treated as an imbecile' and consequently did not trust others anymore, but in general they did not feel restricted in their contacts with peers. They perceived difficulties in social relationships more as a personality trait than as a consequence of the chronic condition. Some YPs also had or had had an intimate relationship or at least were looking for it, and their parents confirmed this:

YP (M; 17; SB): I've got a crush on someone. She's also handicapped, although that's not what I'm specifically looking for.

P: He has just ended a relationship [...], but I'm sure that another girl will come into his life. [...] He keeps his eyes open.

However, parents often saw more limitations for intimate relationships than the YPs themselves.

YP (F; 15; SB): I don't think that my disease restricts me from entering into social or intimate relationships, or that I dare more or less because of my disease.

P: Of course we talk about boyfriends [...] sometimes, but she is [...] absolutely not ready for that.

Young females also spoke about their desire to have children, but were concerned about pregnancy for medical and practical reasons. Their parents shared these concerns, for instance:
YP (F; 18; DM): The only thing I sometimes worry about is having children. Diabetics who plan pregnancy must have blood values between four and seven far in advance.

P: If [my daughter] wants to have children, I think [she] has to overcome a number of obstacles.

With regard to leisure activities, respondents talked about hobbies, going out and other activities with friends. Most of the YPs explained they had multiple leisure activities and therefore led a 'normal' life. In spite of these positive stories, their chronic condition had a great impact on leisure time, for example due to hospitalization or medication. Especially YPs with SB explained that they do not have many friends, because going out in a wheelchair is difficult. Moreover, some parents were very protective towards their children, to the great annoyance of the child:

YP (M; 17; SB): Sometimes I think: well, [...] I can do much more than you think when it comes to organizing things. [My parents] fail to see that.

P: [My son] would like to go out - into town on his own. Well, I don't want to hear about that, because I really do not support that!

Sometimes parents claimed they were not protective, although the child saw this quite differently:

YP (F; 19; JIA): Sometimes I think: just leave me alone, let me do everything I want!

P: [...] If [my daughter] goes to bed late, as she does sometimes, or goes out with friends [...], she needs no fewer than three days to recover. [...] If she thinks that's worth it, she should do it. [...] Yes, that's her responsibility, [...] I don't care.

YPs found it important to be independent with regard to transportation, but some thought they were simply not capable enough to organize transportation. Their parents agreed on this. For instance, a YP and her mother said:

YP (F; 15; SB): I don't organize transportation myself. I don't think I will do that in the future, because it would surely go wrong.

$\mathrm{P}$ : [She] is not independent at all, no. [...] I think this has to do with her disease, because she has no notion of how to do things.

Others saw their dependency with regard to transportation more as 'forced dependency' or, in other words, something caused by their physical condition:

YP (F; 20; CF): [...] For consultations [... ] I just need to go to the hospital. I have a driving license, 
but don't drive to the hospital myself because I get too tired. Therefore, [my parents] always come with me.

P: She is more dependent [...] on us and she absolutely doesn't like that, [but] that's how it is.

\subsection{Healthcare and self-management}

YPs and parents saw self-management of the chronic condition as: taking responsibility for medication, arranging hospital visits, turning up for consultations, talking with caregivers, and making decisions and being responsible to keep to these decisions. Most of the YPs said they were fully responsible for their health status, often stimulated by their parents, who felt that this was the normal course of things:

YP (M; 19; CF): I'm responsible for my medication, [...] because it is my own problem when I forget to take it. My parents also see it this way.

P: It's about trust and, yes, he gets that from us and I suppose it goes well.

YP (F; 20; DM): When I'm in the hospital, I will make a next appointment myself. I simply manage these things myself.

P: Life goes on [...], children are getting older and that's how it goes [...]. Self-management is like when your children go to school by bike for the first time on their own.

YP (F; 22; CHD): [...] Just a conversation [with the doctor] alone, so you can freely talk without parents present.

P: [...] She acts more and more independently, so you need not come [to the hospital] with her. But that's how it should be.

On the other side, there were also YPs who did not feel the need to take full responsibility for medical self-management. They found their parents' help 'quite convenient' so they could 'pay attention to other things'. While these YPs would be capable of managing the chronic condition themselves, their parents do not seem to motivate them to do so. Their parents showed that they have little confidence in their children. Consequently, they had a protective attitude and found it difficult to transfer autonomy:

YP (M; 17; SB): Sometimes they are really worried, [...] they want me to take good care of myself and I don't always do so. [...] They say I should make my own appointments, but still check on it. And all doctors talk with me now, but my father and mother are still present during consultations.
P: You know he will get a bladder infection if he doesn't take good care of himself. [... ] You don't want [this], [...] therefore you're going to tell him what he has to do.

Also, a YP with CF and his mother said:

YP (M; 18; CF): When my father asks me to do something, mostly I do it right away, but he [...] doesn't keep asking. My mother does so and sometimes that really annoys me.

P: They said [in the hospital]: 'You don't have to tell anything to [your son], let him think for himself, let him take his medication on his own, let him spray on his own, let him think what to do.' But that doesn't work for [my son]!

For some YPs the dependency upon their parents was not due to lack of motivation. They were physically restricted to manage fully on their own and their parents agreed:

YP (M; 16; SB): For example, I cannot shower on my own.

P: Other children move naturally towards independency [...], but that's not the case for my son [...]. My son needs me [...], [that's] a big difference, isn't it?

\section{Discussion}

This study sheds light on how young persons with chronic conditions experienced their development towards autonomy in several life areas and how their parents perceived this. The pair-wise interview analyses revealed that parents were sometimes wary to provide room for more independence whereas their children themselves felt ready for this. As a consequence, some young persons felt restricted to follow the road to independence.

Young persons especially disagreed with their parents regarding independent living prospects, being socially engaged, and self-management skills. While young persons wanted to become more autonomous in these life areas, their parents doubted they could. An explanation for this child-parent disagreement may be parental overprotection, which often stems from parents' perception that their child is vulnerable because of the chronic condition or from concerns about their child's capability of taking responsibility for his or her health [19-22]. Sometimes it seemed to parents as if their children did not feel the necessity to take full re- 
sponsibility for their own life and health, which limited confidence in their children. Whereas parents would do well by encouraging their children to proceed on the way to independence [32], the perceived passive attitude of their children might be an explanation for parents keeping control over them. Some parents were torn between the desire to foster independence in their child on the one hand, and the desire to protect the child on the other hand. This type of ambivalence regarding the transition to adulthood has been reported previously [19,20,27].

Child-parent disagreement might also be due to reluctance from the side of children to discuss more private issues with their parents, who then remain ignorant of the child's experiences and wishes. There was also some disagreement on the domain 'me' (agency), as parents sometimes underestimated the young person's sense of self-respect. Discrepancy between selfreports and parent-proxy reports of young person's health-related quality of life has been recognized as the 'proxy problem' [33]. Parents often seem to weigh the impact of the chronic condition more heavily than the young person does. Despite this reality, Sattoe et al. [33] recommended that care providers focus on the young person's own perceptions. Although parents are generally less informed about sensitive issues, they should be encouraged to communicate openly with their children about their lived experiences. Parents should also be made aware of their possible underestimation. Being treated as normal children as much as possible may help the young persons to develop the skills to cope with the challenges of reaching adulthood [34].

Although most young persons in this study did not like parental interference on their road to independence, it is unknown to what extent this finding is related to having a chronic condition or just to adolescence in general. It appears as if parents of young persons with more severe chronic conditions behave more protectively towards their children [19]. However, it may be that these parents are not more protective, but just more supportive and involved because they have to be and because their children need them. For instance, some young persons were dependent on their parents for transportation because of their physical limitations. As they simply had no choice, there was little reason for confrontation with their parents [20]. Indeed, the presence of physical limitations in adolescents with chronic conditions is associated with negative outcomes regarding self-efficacy, independent behavior, and readiness for transfer to adult care [15].
Little child-parent disagreement was seen with regard to education and work, although some young persons missed parental support. Parents tended to be concerned about the children's future perspectives, whereas the children themselves were more concerned with the present challenges. A study of Maurice-Stam et al. [34] revealed that achieving fewer developmental milestones while growing up is expected to reduce the likelihood of labor participation in adulthood. Therefore, parental support in the young person's developmental trajectory is important to achieve successful participation in society and to create conditions for a better labor market position [7,35]. There were also some cases in which young persons did not disagree with their parents at all. These young persons described their lives as dominated by positive experiences, which is in line with previous studies [20,26]. Their parents confirmed this and were often instrumental here. They just let their children live their own lives.

Previous studies showed that child-parent disagreement might have negative consequences on young persons' lived experiences, their social participation and their development to adulthood [19,25]. Our findings suggest that most negative consequences might be experienced in the areas of living independently, intimate relationships, leisure activities, and healthcare. For this reason, healthcare professionals would do well to pay specific attention to self-management support in these areas [35]. It is vital that self-management support not only refers to medical management issues related to therapy and adherence, but is also extended to life span care and skills [36]. The positive youth development perspective provides a novel framework that focuses on developing positive attributes in young persons with special healthcare needs, such as competence, confidence, character, social connectedness, and compassion [37]. This is believed to promote successful adult development and improved disease management for young persons with special healthcare needs, and the ability to advocate for oneself in the healthcare environment. Supporting parents in achieving the required role change deserves attention as well, as parents develop and express their expectations for the child's behavior and skills [1]. Like the young persons, parents should be supported to focus on strengths too, and to develop positive, realistic, and developmentallyappropriate expectations [1]. The SGU tool may be useful in this respect [7,31], as it is based on the shared management model, which gradually describes the transition to adulthood $[38,39]$. Based on the perception of having already acquired the skills or knowl- 
edge referred to in the checklist of the SGU, young persons and their parents can score the items at home [7, 31]. Next, they can choose three items to work on for the coming period, set goals to be achieved, and draft an action plan on how to achieve these goals. This may help them in realizing a discussion in order to get their perceptions more comparable. During medical consultations, care professionals can assist by addressing young persons' goals, for instance by providing training or referral to other professionals [7,31].

\section{Strengths and limitations}

Seeing the scarce literature on experiences of both young persons with chronic conditions and their parents, this study adds value by exploring the similarities and the differences between these two actors when it comes to achieving autonomy during adolescence. The pair-wise analysis used in this study is quite unique in this field of research.

Young persons with different chronic conditions participated in this study, including those with and without physical limitations. However, the total study sample was small, so the results should be considered with some caution. It seems as if young persons with physical disabilities such as SB experience more burden of their condition in their transition to adulthood and in their participation in social life. This is in line with another study demonstrating that young persons with SB tend to be socially immature and passive, and that they are often more dependent on adults for guidance and less likely to make independent decisions [40]. However, we could not make valid comparisons between diagnostic groups, as ages varied widely between groups. The respondents with SB were much younger (between 15-17 years old) than the other young persons (between 18-22 years old). This could explain the differences in life course. Furthermore, the different chronic conditions were not equally represented among the sixteen young persons included in this study. Six out of sixteen respondents suffered from $\mathrm{SB}$, while the other five diagnostic groups each consisted of a maximum of three participants. This skewed distribution must be taken into account too, when interpreting the results.

It might be a limitation that only one father was included in this study, as a study by Holmbeck et al. [19] revealed that mothers act significantly more protectively than fathers towards both children with SB and healthy children. The present study did not allow for investigating gender differences in relation to protec- tive behavior, since predominantly mothers were interviewed. In future research it would be worthwhile to include as many fathers as mothers.

Using the SGU framework made it possible to analyze the data thematically. However, the life area 'sports' was not systematically discussed in the interviews and was, therefore, left out of the analysis. Since participation in sports activities is important not only for physical fitness, but also for leisure and meeting peers, this is a limitation of our study.

\section{Conclusion}

The qualitative paired analysis conducted in this study showed some similarities between the experiences of young persons and their parents concerning the transition towards adulthood. However, on some issues perceptions clashed, notably on themes such as living independently, intimate relationships, leisure activities, and healthcare. To prevent negative outcomes, professional support for young persons to help them deal with more autonomy and the role change with parents might be especially needed for these domains.

\section{Practice implications}

Professionals in pediatric and rehabilitation care would do well to point out the importance of preparing for independent living, participating in relationships and leisure activities with peers, and adopting independent healthcare behaviors for young persons with chronic conditions. They should offer young persons and their parents tools that could help them in realizing a discussion in order to get their perceptions more in line. Self-management promoting interventions, such as the SGU tool [31] and the Rotterdam Transition Profile [3], could be helpful both at home and in the consultation room. Furthermore, the HEADSS screening tool (Home - Education/Exercise - Activities/Affect/Ambition - Drugs and substance abuse/Driving/Diet and weight management - Sleep/Sexual health) will help professionals identify (psychosocial) risk factors in young persons with chronic conditions [41]. This tool provides a basis for a 'safe' discussion of sensitive issues, so that professionals can address specific problems. In order to get used to such tools and to help professionals incorporate them into their working routines, professionals need additional training. 


\section{Acknowledgements}

No external funding was available for this study. The researchers would like to thank the members of the On Your Own Feet Research Group for their contributions to the study design and data collection. The researchers would also like to thank the young people formerly treated in the Erasmus MC - Sophia Children's Hospital and their parents for participating in the study. Furthermore, in preparing this manuscript the researchers benefitted from feedback by Jane Sattoe and Ko Hagoort.

\section{Conflict of interest}

The authors report no conflicts of interest.

\section{References}

[1] K.B. Blomquist, G. Brown, A. Peersen and E.P. Presler, Transitioning to independence: challenges for young people with disabilities and their caregivers, Orthop Nurs 17(3) (1998), 27-35.

[2] S. Kirk, Transitions in the lives of young people with complex healthcare needs, Child Care Health Dev 34(5) (2008), 56775.

[3] M. Donkervoort, D.J.H.G. Wiegerink, J. Meeteren van, H.J. Stam and M.E. Roebroeck, Transition to adulthood: validation of the Rotterdam Transition Profile for young adults with cerebral palsy and normal intelligence, Dev Med Child Neurol 51(1) (2009), 53-62.

[4] L. Haverman, E.J. Verhoof, H. Maurice-Stam, H.S. Heymans, D.M. Gerlag, M.A. van Rossum et al., Health-related quality of life and psychosocial developmental trajectory in young female beneficiaries with JIA, Rheumatology (Oxford) 51(2) (2012), 368-374

[5] W. Martinez, J.S. Carter and L.J. Legato, Social competence in children with chronic illness: A meta-analytic review, $J$ Pediatr Psychol 36(8) (2011), 878-890.

[6] H. Maurice-Stam, E.E. Hartman, J.A. Deurloo, J. Groothoff and M.A. Grootenhuis, Young adult patients with a history of pediatric disease: Impact on course of life and transition into adulthood, J Adolesc Health 39(1) (2006), 4-13.

[7] J.N.T. Sattoe, S.R. Hilberink, M.A.C. Peeters and A.L. van Staa, 'Skills for Growing Up': supporting autonomy in young people with renal disease, Journal of Renal Care, 2013, In press.

[8] H.A. Barf, M. Verhoef, M.W. Post, A. Jennekens-Schinkel, R.H. Gooskens, R.A. Mullaart et al., Educational career and predictors of type of education in young adults with spina bifida, Int J Rehabil Res 27(1) (2004), 45-52.

[9] I. Plug, M. Peters, E.P. Mauser-Bunschoten, A. de GoedeBolder, L. Heijnen, C. Smit et al., Social participation of patients with hemophilia in the Netherlands, Blood 111(4) (2008), 1811-1815.
[10] M. Verhoef, H.A. Barf, J.A. Vroege, M.W. Post, F.W. van Asbeck, R.H. Gooskens et al., Sex education, relationships, and sexuality in young adults with spina bifida, Arch Phys Med Rehabil 86(5) (2005), 979-987.

[11] E. Verhoof, H. Maurice-Stam, H. Heymans and M. Grootenhuis, Growing into disability benefits? Psychosocial course of life of young adults with a chronic somatic disease or disability, Acta Paediatr 101(1) (2012), e19-26.

[12] D.J. Wiegerink, M.E. Roebroeck, M. Donkervoort, P.T. Cohen-Kettenis and H.J. Stam, Social, intimate and sexual relationships of adolescents with cerebral palsy compared with able-bodied age-mates, J Rehabil Med 40(2) (2008), 112-118.

[13] P.W. Newacheck, M.A. McManus and H.B. Fox, Prevalence and impact of chronic illness among adolescents, Am J Dis Child 145(12) (1991), 1367-1373.

[14] G. Sinnema, Youths with chronic illness and disability on their way to social and economic participation: A health-care perspective, J Adolesc Health 13(5) (1992), 369-371.

[15] A.L. van Staa, H.A. van der Stege, S. Jedeloo, H.A. Moll and S. Hilberink, Readiness to transfer to adult care of adolescents with chronic conditions: exploration of associated factors, $J$ Adolesc Health 48(3) (2011), 295-302.

[16] M.E. Roebroeck, R. Jahnsen, C. Carona, R.M. Kent and M.A. Chamberlain, Adult outcomes and lifespan issues for people with childhood-onset physical disability, Dev Med Child Neurol 51(8) (2009), 670-678.

[17] M.G. Sawyer, K.E. Reynolds, J.J. Couper, D.J. French, D. Kennedy, J. Martin et al., A two-year prospective study of the health-related quality of life of children with chronic illnessthe parents' perspective, Qual Life Res 14(2) (2005), 395405.

[18] R.M. Viner, Transition of care from paediatric to adult services: One part of improved health services for adolescents, Arch Dis Child 93(2) (2008), 160-163.

[19] G.N. Holmbeck, S.Z. Johnson, K.E. Wills, W. McKernon, B. Rose, S. Erklin et al., Observed and perceived parental overprotection in relation to psychosocial adjustment in preadolescents with a physical disability: The mediational role of behavioral autonomy, J Consult Clin Psychol 70(1) (2002), 96110.

[20] C. Eiser and J.L. Berrenberg, Assessing the impact of chronic disease on the relationship between parents and their adolescents, J Psychosom Res 39(2) (1995), 109-114.

21] A.L. van Staa, On Your Own Feet Research Group. Unraveling triadic communication in hospital consultations with adolescents with chronic conditions: The added value of mixed methods research, Patient Educ Couns 82(3) (2011), 455464.

[22] I.P. Vermaes, J.R. Gerris and J.M. Janssens, Parents' social adjustment in families of children with spina bifida: A theorydriven review, J Pediatr Psychol 32(10) (2007), 1214-1226.

[23] D. Oeffinger, G. Gorton, A. Bagley, D. Nicholson, D. Barnes, J. Calmes et al., Outcome assessments in children with cerebral palsy, part I: descriptive characteristics of GMFCS Levels I to III, Dev Med Child Neurol 49(3) (2007), 172-180.

[24] V.A. Miller, Parent-child collaborative decision making for the management of chronic illness: A qualitative analysis, Fam Syst Health 27(3) (2009), 249-266.

[25] B. Beresford, On the road to nowhere? Young disabled people and transition, Child Care Health Dev 30(6) (2004), 581-587.

[26] J.C. Surís, P.A. Michaud and R. Viner, The adolescent with a chronic condition. Part I: developmental issues, Arch Dis Child 89(10) (2004), 938-942.

[27] A.L. van Staa, S. Jedeloo, J. van Meeteren and J.M. Latour, 
Crossing the transition chasm: experiences and recommendations for improving transitional care of young adults, parents and providers, Child Care Health Dev 37(6) (2011), 821-832.

[28] W.L. Neuman, Social Research Methods: Qualitative and Quantitative Approaches. 7th ed. Boston: Allyn and Bacon, 2011.

[29] K.F. Hyde, Recognising deductive processes in qualitative research, Qualitative Market Research: An International Journal 3(2) (2000), 82-89.

[30] M.B. Miles and A.M. Huberman, Qualitative data analysis: An expanded sourcebook. 2nd ed. London: Sage Publications, 1994.

[31] C.G.B. Maathuis, I. Vos, M.E. Roebroeck and S.R. Hilberink, Een instrument om vaardigheden voor zelfstandigheid te vergroten: De Groei-wijzer [A tool to increase skills for independence: The Skills for Growing Up], Nederlands Tijdschrift voor Revalidatiegeneeskunde 34(3) (2012), 115-119.

[32] L.K. Brunton and D.J. Bartlett, The bodily experience of cerebral palsy: A journey to self-awareness, Disabil Rehabil (2013), 1-10.

[33] J.N.T. Sattoe, A.L. van Staa and H.A. Moll, On Your Own Feet Research Group. The proxy problem anatomized: childparent disagreement in health related quality of life reports of chronically ill adolescents, Health Qual Life Outcomes $\mathbf{1 0}$ (2012), 10.

[34] H. Maurice-Stam, E.J. Verhoof, H.N. Caron and M.A. Grootenhuis, Are survivors of childhood cancer with an unfavourable psychosocial developmental trajectory more likely to apply for disability benefits? Psycho-Oncology 22(3) (2013), 708-714

[35] S. Kingsnorth, H. Healy and C. Macarthur, Preparing for adulthood: A systematic review of life skill programs for youth with physical disabilities, J Adolesc Health 41(4) (2007), 323-332.

[36] G.M. Kieckhefer and C.M. Trahms, Supporting development of children with chronic conditions: from compliance toward shared management, Pediatr Nurs 26(4) (2000), 354-363.

[37] G. Maslow, C. Adams, M. Willis, J. Neukirch, K. Herts, W. Froehlich et al., An evaluation of a positive youth development program for adolescents with chronic illness, $J$ Adolesc Health 52(2) (2013), 179-185.

[38] C. Gall, S. Kingsnorth and H. Healy, Growing up ready: A shared mangement approach, Phys Occup Ther Pediatr 26(4) (2006), 47:62.

[39] G.M. Kieckhefer, A shared management approach to transition. Paper presented at the Hospital for Sick Children, Toronto, ON

[40] G.N. Holmbeck, V.C. Westhoven, W.S. Phillips, R. Bowers, C. Gruse, T. Nikolopoulos et al., A multimethod, multiinformant, and multidimensional perspective on psychosocial adjustment in preadolescents with spina bifida, J Consult Clin Psychol 71(4) (2003), 782-796.

[41] J.M. Goldenring and D.S. Rosen, Getting into adolescent heads: An essential update, Contemporary Pediatrics 21(1) (2004), 64-90. 